\title{
Nove vrste i nomenklaturne preinake u popisu flore Hrvatske - 4
}

\author{
VEDRAN ŠEGOTA ${ }^{1}$, SANDRO BOGDANOVIĆ ${ }^{2 *}$ \\ ${ }^{1}$ Sveučilište u Zagrebu, Prirodoslovno-matematički fakultet, Biološki odsjek, Botanički zavod, \\ Marulićev trg 9a, HR-10000 Zagreb, Hrvatska \\ ${ }^{2}$ Sveučilište u Zagrebu, Agronomski fakultet, Zavod za poljoprivrednu botaniku, Svetošimunska 25, \\ HR-10000 Zagreb, Hrvatska
}

*Autor za dopisivanje / corresponding author: sbogdanovic@agr.hr

Tip članka / article type: kratko stručno priopćenje / short professional communication

Povijest članka / article history: primljeno / received: 22.12.2020., prihvaćeno / accepted: 23.12. 2020.

URL: https://doi.org/10.46232/glashbod.8.2.5

\section{Šegota, V., Bogdanović, S. (2020): Nove vrste i nomenklaturne preinake u popisu flore Hrvatske} - 4. Glas. Hrvat. bot. druš. 8(2): 108-112.

\section{Sažetak}

Dosad su u Glasniku Hrvatskog botaničkog društva objavljena tri priloga koja popis flore Hrvatske i bazu podataka Flora Croatica (http://hirc.botanic.hr/fcd) dopunjuju s novoopisanim i novootkrivenim biljnim svojtama te se provode nomenklaturne preinake već postojećih svojti. Kako bi se taj niz i dalje nastavio, ovaj prilog je četvrti u nizu te je u bazu podataka Flora Croatica dodano sedam novih biljnih svojti (Glaux maritima L., Cystopteris dickieana R. Sim, Teucrium x rohlenae K. Malý, Helianthemum jonium Lacaita \& Grosser ex Bég., Ornithogalum sibthorpii Greuter, Carex phyllostachys C. A. Mey. i Amaranthus tuberculatus (Moq.) J.D. Sauer) koje se po prvi puta bilježe za Hrvatsku.

Ključne riječi: baza podataka Flora Croatica, flora, nomenklatura, nove vrste, taksonomija

Šegota, V., Bogdanović, S. (2020): New species and nomenclatural changes in the checklist of the Croatian flora - 4. Glas. Hrvat. bot. druš. 8(2): 108-112.

\section{Abstract}

Till now in the Journal of the Croatian Botanical Society three contributions were published that serve as an update of the Flora Croatica Database (http://hirc.botanic.hr/fcd) with new entries of a newly described plant taxa and new discovered taxa in the flora, as well as nomenclatural changes were applied on already existing plant taxa. In order to continue this series, this contribution is the fourth in a series and seven new plant taxa (Glaux maritima L., Cystopteris dickieana R. Sim, Teucrium x rohlenae K. Malý, Helianthemum jonium Lacaita \& Grosser ex Bég., Ornithogalum sibthorpii Greuter, Carex phyllostachys C. A. Mey. i Amaranthus tuberculatus (Moq.) J.D. Sauer) have been added to the Flora Croatica Database, which are being recorded for the first time in Croatia. 
U bazu podataka Flora Croatica (Nikolić 2020) dodano je sedam novih biljnih svojti koje se po prvi puta bilježe za Hrvatsku, a to su:

\section{Glaux maritima L.}

Mjesto prvog objavljivanja: Sp. Pl. 207 (1753)

Sinonim: Lysimachia maritima (L.) Galasso, Banfi \& Soldano, Atti Soc. Ital. Sci. Nat. Mus. Civico Storia Nat. Milano 146(2): 229 (2005)

Nalazišta u Hrvatskoj: uz rijeku Zrmanju blizu Obrovca (preuzeto iz Alegro i sur. 2019)

Glaux maritima (Sl. 1A) je mala višegodišnja vrsta iz porodice jaglaca (Primulaceae) koja raste na slanim i braktičnim obalama sjeverne hemisfere, te intrakontinentalnim slatinama (cirkumholarktički florni element). Mala populacija ove vrste pronađena je 2017. u subhalofilnoj vegetaciji uz obalu rijeke Zrmanje kod Obrovca. Ovo je prvi nalaz za Hrvatsku i jugoistočnu Europu, te treći za Sredozemlje (nakon Španjolske i azijskog dijela Turske). Zbog male veličine populacije i ugroženog staništa predložena je klasifikacija u kategoriju kritično ugrožene vrste (Alegro i sur. 2019).

\section{Cystopteris dickieana R. Sim}

Mjesto prvog objavljivanja: Gard. Farmers' J. 2: 308 (1848)

Sinonimi: Cystopteris baenitzii Dörfl., Herb. Eur. n. 6510 (1891); C. fragilis (L.) Bernh. var. baenitzii (Dörfl.) Asch. \& Graebn., Syn. Mitteleur. Fl. 1: 17 (1896); C. fragilis (L.) Bernh. subsp. dickieana (R. Sim) Hyl., Uppsala Univ. Arsskr. 1945(7): 59 (1945); C. fragilis (L.) Bernh. f. granulose Bir. \& Trikha, Amer. Fern J. 66(3): 109 (1976); C. fragilis (L.) Bernh. var. dickieana (R. Sim) T. Moore, Index Fil. 282 (1861)

Nalazišta u Hrvatskoj: Južni Velebit, blizu Svetog Roka (preuzeto iz Mei i sur. 2020)

Cystopteris dickieana (Sl. 1B) je rijetka cirkumholarktička vrsta paprati iz porodice Woodsiaceae. Otkriće male populacije na južnom Velebitu 2018. prvi je nalaz ove vrste u Hrvatskoj i u sjeverozapadnom dijelu Balkanskog poluotoka. Ova slabo poznata vrsta pripada kompleksu C. fragilis, unutar kojih se vrste razlikuju po skulpturiranosti površine spora (Mei i sur. 2020).

\section{Amaranthus tuberculatus (Moq.) J.D. Sauer}

Mjesto prvog objavljivanja: Madroño 13: 18 (1955)

Sinonimi: Amaranthus rudis J. D. Sauer, Madroño 21: 428 (1972)

Nalazišta u Hrvatskoj: uz rijeku Savu i pritoke, od Jelas polja do Slavonskog Šamca (preuzeto iz Rimac i sur. 2020)

Amaranthus tuberculatus (Sl. 1C) je jednogodišnja korovna vrsta iz porodice Amaranthaceae koja potječe iz Sjeverne Amerike, a uvezena je u Europu i Aziju. Tijekom 2019. po prvi puta je zabilježena u Hrvatskoj, što je nakon nalaza u delti Dunava u Rumunjskoj drugi nalaz u jugoistočnoj Europi. Jedinke oba spola zabilježene su na ukupno 19 lokacija u Panonskoj Hrvatskoj, najčešće u vegetaciji niskih šaševa i poplavnih, nutrijentima bogatih riječnih obala Save (Rimac i sur. 2020). Predloženo je hrvatsko ime vrste kvržićavi šćir.

\section{Carex phyllostachys C. A. Mey.}

Mjesto prvog objavljivanja: Verz. Pfl. Casp. Meer. (C. A. von Meyer). 30 (1831)

Sinonimi: Forexeta phyllostachys (C. A. Mey.) Raf., Good Book 28 (1840)

Nalazišta u Hrvatskoj: dosad je planina Mosor jedini poznati lokalitet ove vrste (preuzeto iz Terlević i sur. 2021)

Carex phyllostachys (Sl. 1D) je rijetka Euro-Kavkaska vrsta iz porodice Cyperaceae koja je otkrivena po prvi puta u lipnju 2019. god. u prizemnom sloju listopadne šume hrasta medunca i bijelog graba (Quercus pubescens-Carpinus orientalis) na Mosoru. Ova vrsta je morfološki slična vrstama C. illegitima Ces. i C. distachya Desf. te zajedno pripadaju u subgen. Indocarex (Terlević i sur. 2021). 

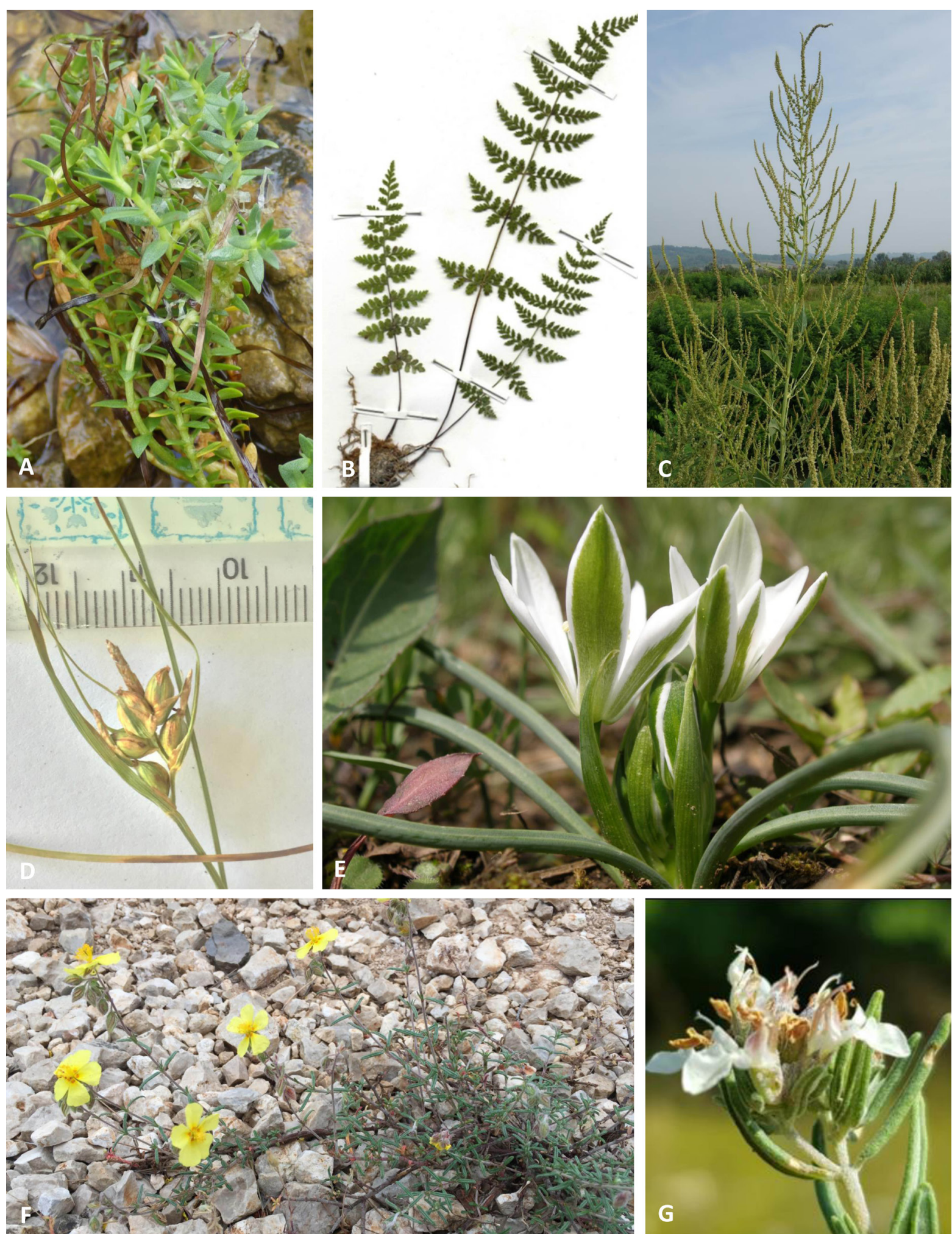

Slika 1. Glaux maritima (A), Cystopteris dickieana (B), Amaranthus tuberculatus (C), Carex phyllostachys (D), Ornithogalum sibthorpii (E), Helianthemum jonium (F), Teucrium $\mathrm{x}$ rohlenae (G). 


\section{Ornithogalum sibthorpii Greuter}

Mjesto prvog objavljivanja: Boissiera 13: 160 (1967)

Sinonimi: Ornithogalum nanum Smith in Sibth. et Smith, Fl. Graec. Prodr. 1: 230 (1809); Fl. Graec. (Sibthorp). 4: 28, t. 333 (1823); non O. nanum (Burm. f.) Thunb., Prodr. Fl. Cap. 62 (1794)

Nalazišta u Hrvatskoj: Donji Lapac, Nin, Sukošan, Split, Makarska, Orebić na Pelješcu, Cavtat i Brgat kod Dubrovnika (preuzeto iz Rat i Bogdanović 2021).

Ornithogalum sibthorpii (Sl. 1E) je ranocvjetajuća proljetna vrsta iz porodice Asparagaceae čije su populacije raštrkano rasprostranjene na Balkanskom poluotoku i u Turskoj. Vrsta raste na kamenjarskim mjestima, otvorenim staništima, uz rubove vlažnih livada te u parkovima. Na temelju revizije herbarijskog materijala i terenskih istraživanja, vrsta $O$. sibthorpii je potvrđena u hrvatskoj flori na nekoliko lokaliteta duž jadranske obale te u Lici, a nakon provedene citološke analize utvrđeno je da su sve populacije diploidne s brojem kromosoma $2 n=18$. Morfološki je slična vrsti $O$. excapum od koje se razlikuje po tome što ima potpuno podzemni batvo, donje cvjetne stapke za vrijeme cvatnje do $3 \mathrm{~cm}$ duge i potpuno svijene, jasno razvijen lisni jastučić (pulvinus) na bazi cvjetnih stapki te brakteje gotovo jednako dugačke kao i same stapke (Rat i Bogdanović 2021).

\section{Helianthemum jonium Lacaita \& Grosser ex Bég.}

Mjesto prvog objavljivanja: Nuovo Gior. Bot. Ital., nov. ser., 17: 609 (1910)

Sinonimi: H. leptophyllum sensu E. Groves, Nuovo Giorn. Bot. Ital. 19: 127 (1887); non Dunal. in DC., Prodr. 1: 279 (1824); H. leptohyllum Dunal var. eulepthophyllum Gross., Pflanzenreich 14, IV. 193: 69 (1903); H. chamaecistus Mill. var. jonium (Lacaita \& Gross.) Fiori, Nuova Fl. Anal. Ital. 1: 532 (1925)

Nalazišta u Hrvatskoj: otoci Biševo, Vis, Hvar i Lopud (preuzeto iz Bogdanović i sur. 2019)
Prisutnost vrste Helianthemum jonium (Sl. 1F) koja pripada porodici Cistaceae po prvi puta je zabilježena i dokumentirana u flori Hrvatske i Crne Gore te je potvrđena u flori Albanije nakon 80 godina. Vrsta raste na pješčanim tlima unutar vegetacije makije i gariga na četiri jadranska otoka: Vis, Biševo, Hvar i Lopud te unutar psamofilne vegetacije kod Ulcinja (Crna Gora) i kod Drača (Albanija). Vrsta $H$. jonium prethodno je bila poznata jedino s Apeninskog poluotoka, a nova nalazišta $u$ istočnom Jadranu pridonose istočnom proširenju granice areala vrste te se ista mora smatrati amfi-jadranskim endemičnim elementom.

\section{Teucrium x rohlenae K. Malý}

Mjesto prvog objavljivanja: Fl. Bosn. \& Hercegov. IV. Sympet. 1: 29 (1950)

Nalazišta u Hrvatskoj: Bisko kod Trilja i planina Matokit kod Vrgorca (preuzeto iz Zbiljić i sur. 2021) Teucrium $\mathrm{x}$ rohlenae je hibridna svojta (Sl. 1G) iz porodice Lamiaceae koja je nastala spontanim križanjem T. montanum L. i T. polium L. subsp. capitatum (L.) Arcang., a po prvi puta je opisana iz okolice Kotora u Crnoj Gori. Na temelju morfološke i fitokemijske analize po prvi puta je otkriveno njezino prisustvo u Hrvatskoj (okolica Trilja i planina Matokit) te je potvrđena u Crnoj Gori (Zbiljić i sur. 2021).

\section{Literatura}

Alegro, A., Šegota, V., Koletić, N., Vuković, N., Vilović, T., Rimac, A. (2019): Glaux maritima L. (Primulaceae), a new plant species in SE Europe. Acta Botanica Croatica 78(1): 95-98.

Bogdanović, S., Holcer, D., Janev Holcer, N., Shuka, L. (2020): Helianthemum jonium (Cistaceae), a new species in the eastern Adriatic. Natura Croatica 29(1): 9-18.

Mei, G., Šegota, V., Stinca, A., Vukelić, J., Baričević, D., Taffetani, F., Alegro, A. (2020): Cystopteris dickieana R. Sim (Cystopteridaceae), a new fern in the continental Balkans flora. Plant biosystems, doi: 10.1080/11263504.2020.1799103 
Nikolić, T. (ur.) (2020): Flora Croatica Database. Terlević, A., Koopman, J., Więcław, H., Rešetnik, I., Flora Croatica Database. Sveučilište u Zagrebu, Bogdanović, S. (2021): Carex phyllostachys (CypePrirodoslovno-matematički fakultet, Botanički zavod s botaničkim vrtom, Zagreb. http://hirc. botanic.hr/fcd/ (pristupljeno 20. listopada 2020.).

Rat, M., Bogdanović, S. (2021): Ornithogalum sibthorpii Greuter (Asparagaceae), an overlooked species in Croatia. Acta Botanica Croatica 80(1), doi: $10.37427 /$ botcro-2021-003

Rimac, A., Doboš, M., Šegota, V. (2020): Amaranthus raceae), a new species in Croatia. Acta Botanica Croatica 80(1), doi: 10.37427/botcro-2021-002

Zbiljić, M., Lakušić, B., Marčetić, M., Bogdanović, S., Lakušić, D. (2021): Morphological and chemical evidence of Teucrium $\times$ rohlenae K.Malý (Lamiaceae), a new hybrid in Croatia. Acta Botanica Croatica 80(1), doi: 10.37427/botcro-2020-033 tuberculatus (Moq.) J. D. Sauer - a new alien pigweed species in Croatia. BioInvasions Records 9(3): 642-654. 